\title{
Increasing Community discourse and Action on GBV prevention in Akai Effa and Idundu, Cross River State
}

\author{
Edisua Merab Yta ${ }^{1}$, Gloria Mayen Umukoro² ${ }^{2}$, Moses Essien Ekpe ${ }^{3}$ \\ ${ }^{1}$ Department of Theatre, Film and Carnival Studies Studies. \\ University of Calabar, Cross River, Nigeria \\ ${ }^{2}$ Department of Modern Languages and Translation Studies \\ University of Calabar, Cross River, Nigeria \\ ${ }^{3}$ Department of Public Health, \\ University of Calabar, Cross River, Nigeria \\ Email: edisuamerab@gmail.com ${ }^{1}$
}

(Received: May-2020; Reviewed: July-2020; Accepted: July-2020; Available Online: July2020; Published: September-2020)

\begin{abstract}
Gender-Based Violence is an issue of high global concern and has serious implications for every aspect of women's lives. The aim of the study was twofold, to increase awareness and knowledge of community members on the contexts in which GBV occurs through the narrative based methodology. It also sought to generate community actions and stem the tide of gender-based violence in Akai Effa and Idundu, Cross River State. The work used a creative narrative based research methodology to explore the contexts in which GBV and inequalities occur. The study had several phases including advocacy visits, production of films, film tours, and the formation of neighbourhood committees. The film "Women of our Land" was a collage of various scenes from different authors produced by DreamBoat Theatre for Development Foundation including; Tess Onwume's 'The Broken Calabash' and 'The Reign of Wazobia', Edisua Yta's 'Because I am a woman' and 'Wives, mothers and daughters' TV, and radio serials, Liwhu Betiang's 'The First Stone', Data Phido's 'Rainbow City' and Chris Nwamuo's 'The Substitute'. The film (an entereducate strategy) was used as a starting point for dialogues in the communities. About three hundred community members were involved in Akai Effa and Idundu and the project ran for six months. Findings identified the following factors as manifestations of gender-based violence in the communities: Domestic violence especially wife battery, sexual abuse, harassment and rape of young girls, restriction placed on women's economic activities, loss of land, assets, and properties, forceful ejections, and young girls denied opportunities to go to school. It is recommended that an extension of project time is essential to allow for adequate behaviour change and stamp out GBV in our communities.
\end{abstract}

Keywords: Gender-based violence; discourse; local action. 


\section{INTRODUCTION}

Gender-Based Violence (GBV) is an issue of high global concern (Renzetti 2005). GBV is defined as any harm or suffering perpetrated against women, girls, boys, or men and hurts the physical, sexual or psychological health of the individual (Peate 2019). The cause is rooted in gender-based discrimination, inequalities, and unequal power relations. There is a range of GBV including Rape, FGM, Early and Forced Marriage, Human trafficking, and harmful traditional practices (Bassey \& Bubu 2019). GBV cuts across cultures, wealth, religions, age, and sexual orientation. Women and girls are worst affected by GBV.

Globally, it is estimated that as many as $38 \%$ of murders of women and girls are committed by intimate partners. The WHO estimates indicate that at least one in every three women world over will be beaten, raped, or otherwise abused during her lifetime and in most cases, the abuser is a member of her own family (Webster 2019). Also, Violence against women and girls' kills and disables as many women ages 15-44 more than cancer, and the toll on women and girls' health is far more than that of traffic accidents and malaria combined.

Nigeria has a large population of child brides in Africa; the prevalence of GBV is high in Sub-Saharan Africa (Chika 2012). Nigeria accounts for the third-highest number of women and girls who have undergone FGM reported at $25 \%$ prevalence (Ajodo-Adebanjoko 2016). GBV is on the increase in Cross River State, recent data from a UNFPA research shows the following $65.5 \%$ of women of reproductive age in Cross River State have experienced physical violence since age 15 (Njoku et al., 2020). The proportion of women of childbearing age who have experienced sexual violence is $20 \%$ in Nigeria. Spousal violence is highest in Cross River State placed at $47.4 \%$. $25.4 \%$ of women in the state have experienced FGM. Maternal mortality is 54.5 per 100,000 live births.

Gloria Umukoro (2015) also exposes the sexual violence suffered by girls of ages between 15 and 23 during the Calabar Christmas festival. The study revealed that between 2010 and 2013 the number of rape cases reported at different tourism sites and tourism events was on the rise. Thus, reducing gender inequality and violence is a global health and development priority (United Nations General Assembly, World Health Organization). Gender inequality affects human health and wellbeing and has severe consequences for women and girls (Uko 2004; Endong 2017).

Systemic indicators of inequality include disparities in levels of education, political participation (Ibok \& Ogar 2018; Umukoro and Egbai 2016) economic participation, and poverty; social indicators of inequality include restrictive gender norms and gender-based violence. These systemic and social factors intersect to cause adverse health outcomes and inequalities for women. In Nigeria, where girls and women significantly trail boys and men on indicators of inequality, transforming norms and systems that reinforce gender disparities is crucial for achieving development and community health goals. Transforming gender-based violence requires an understanding of the context in which gender inequality occurs.

Globalization and the demands of modern-day living have opened up most communities (Edor 2015; Edor \& Ayuk 2020). They no longer have a homogeneous culture. Migrants have introduced new ways of being and living. (Mayen 2018) identifies these new ways as a mixed or diasporic culture. The same is true in Efik communities of Cross River State. Efik people are known to have a gender-friendly culture, today there are changes as poverty, illiteracy amongst other factors have weakened the fabrics of once knitted communities. Gender-based violence, inequalities, and discrimination have crept in. There is gender differential in several ways including the use of land, allocating resources et al. (Yta 2018). This work set out to examine and understand some of the contexts in which gender-based violence occurs in two Efik speaking communities. The objectives of this work were: 1) To create awareness and increase 
knowledge of community members on the contexts in which gender-based violence occur through increasing community dialogue in Akai Effa and Idundu, 2) To generate local actions and stem the tide of gender-based violence in Akai Effa and Idundu communities.

\section{METHOD}

The work used narrative-based research methods to explore the situations in which gender-based violence and gender inequality occur. The study had several phases, it began with the creation of the film, "Women of our Land"

The film Women of our land is an entertainment-education project. It combined entertainment with the pro-social message of women's human rights education. It integrated theory and performance to illuminate the theatre's communication process with actual viewers. In designing the film, Albert Bandura's Social Cognitive Theory was employed to design an entertainment-education film for communicating messages on women's rights. According to Bandura's theory, people who identify with stage heroes will model characters in the Entertainment-Education film 'Women of our Land' and citizens could identify with and possibly motivate them to embrace human rights practices.

The work used the in textuality approach to scripting. It is a post-modern technique. The work is a collage or pastiche of scenes from various plays. It is episodic. It borrowed scenes from different plays -Tess Onwueme's, The Reign of Wazobia and The Broken Calabash, Liwhu Betiang's The First Stone, Edisua Merab's Because I am a woman, Chris Nwamuo's The Substitute, and Data Phido's Rainbow City to make up the film.

The objective of the work is to educate targeted community members of Akai Effa and Idundu about the rights of women. The work discussed many critical areas of women's rights as shown in the various scenes in the one hour film:

1. Right of women to equal participation in the economic decision, and the right to work and receive wages

2. The right of women to own land, property, and inheritance.

3. Right of the girl child to education, reproductive right to determine when to have a child, to decide whether or not to be pregnant and who to marry

4. Right not to be forced into early marriage

5. The right to freedom from violence and all forms of harmful customary practices

6. The human right to freedom from sexual abuse

7. The right to freedom of expression and opinion

8. The right to equality between men and women and to full and equal partnership in the family and society.

9. The right of women to be free from violence

The entire process was preceded by formative research, episodic treatment, and pilot testing before recording. Thereafter, post-production was done. The film was pilot tested in urban slums. Afterward, advocacy visits were conducted in project communities, followed by the film tours and the formation of neighborhood committee. The study procedures were discussed with M\& E and Gender Experts in the University of Calabar, UNFPA, and Goethe Institut.

Advocacy Visits; Teammates from DreamBoat paid visits to the gatekeepers and community chiefs in the two communities:

i. To introduce the project

ii. Get their support and buy in to roll out the project in their community

iii. Debrief them on Gender issues in the nation/Cross River State

iv. Get them to help in mobilizing and recruiting community members to be part of the project 
Each visit did not last more than 90 minutes; the Chief in Akai Effa agreed that there were gender issues in her community. Chief Hennetta of Akai Effa gave us an open door into her community she requested to have up to a hundred and fifty in her community. According to her, there are gender issues, this is a good opportunity to bring them to the open.

We could only take about seventy

She also wanted to know if there would be more than an education session

The male chief in Idundu argued vehemently that there was no such problem in his community and that the statistical data presented in a verified source including UNFPA was made-up and such not be taken seriously.

It took time to be able to work in Idundu community as the chief kept postponing the engagement saying he had serious engagement either with the State government or other stakeholders. DreamBoat even had to engage some opinion leaders in that community informally before they were able to allow DreamBoat into Idundu for the Film tour.

This work used Albert Bandura and Richard Walter's theoretical framework, Albert Bandura is a Stanford and one of the most influential psychologists of all time. Bandura became popularly known when he conceptualized the Social Learning Theory. In Social Learning and Personality Development, Bandura split out the principles of Social Learning Theory concisely (Bandura \& Walters 1963). He presupposes that individuals and groups learn behavior by observing role models on television. According to him, learning is not purely behavioural, rather, it is a cognitive process that takes place in the social context. Of great interest to us is how Social Learning Theory is applied to creating social change using the media channels (Bandura \& Walters 1963).

Positive social behaviours are reinforced with rewards and negative social behaviours are reinforced with punishment. Through observational learning, a model can bring forth new ways of thinking and behaving. With a modelled emotional experience, the observer shows an affinity towards people, places, and objects. They dislike what the models do not like and like what the models care about. Media representations gain influence because people's social contractions of reality depend heavily on what they see, hear, and read rather than what they experience directly. Efforts to change beliefs must be directed towards the socio-cultural norms and practices at the social system level (Ventevogel 1996).

The above argument has implications for our study. We applied the principles of Social Learning Theory to construct Woman of our Land Entertainment-Education film. The film design allowed the creators to incorporate elements that can bring the desired responses. These elements included actors, music, melodrama, props, and costumes. Entertainment-Education is symbolic modelling and has a formula with three sets of characters with the cultural value that is to be examined is determined ahead of time.

i. Characters that support a value (positive role models) - in this case, women's rights

ii. Characters who reject the value (negative role models) - that reject and oppose women's rights

iii. Characters who have doubts about the value (undecided). - who are neutral

Within the formula team of designers created three sets of doubters that represent the demographic group within the target population. One of these doubters accepted the value less than halfway through the serial, the second accepted the value two-thirds of the way through the serial and the third doubter does not accept the value and is seriously punished. This doubter is usually killed or meets with some catastrophe. 

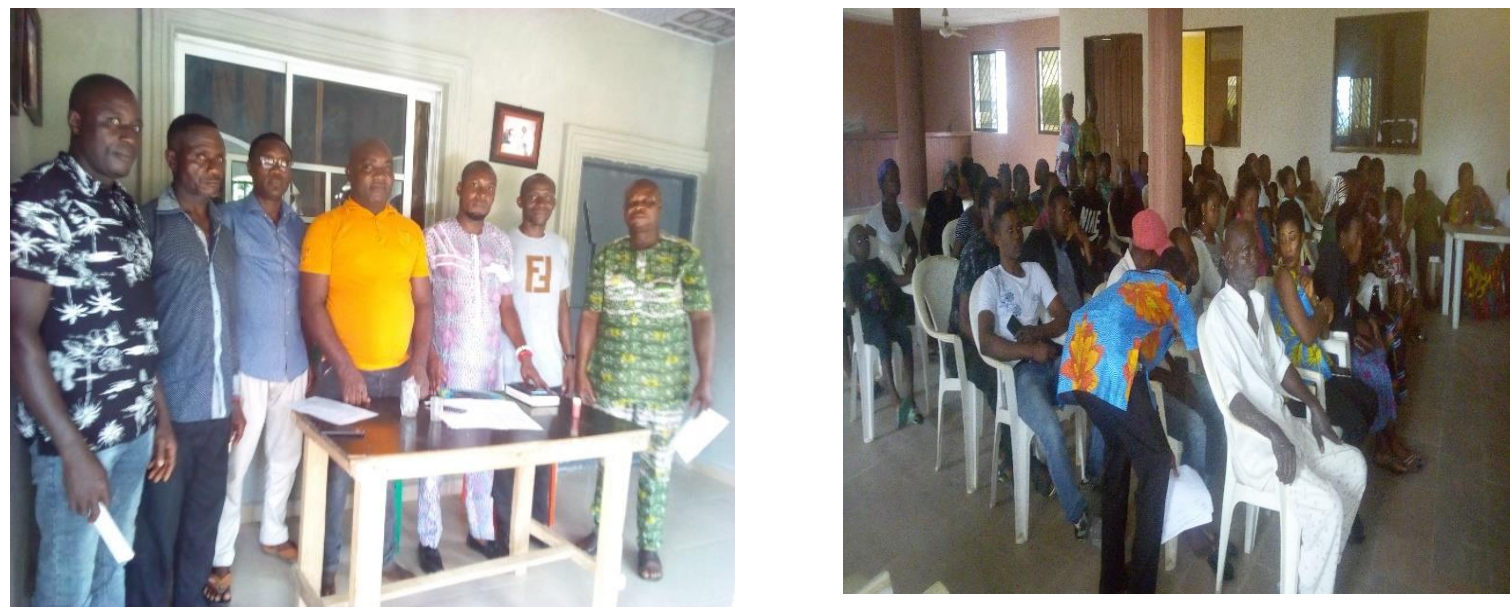

DreamBoat Team Photograph with some Cabinet members in Idundu community, Akpabuyo during advocacy visits

Community members getting ready for the commencement of the "Women of our Land Film"
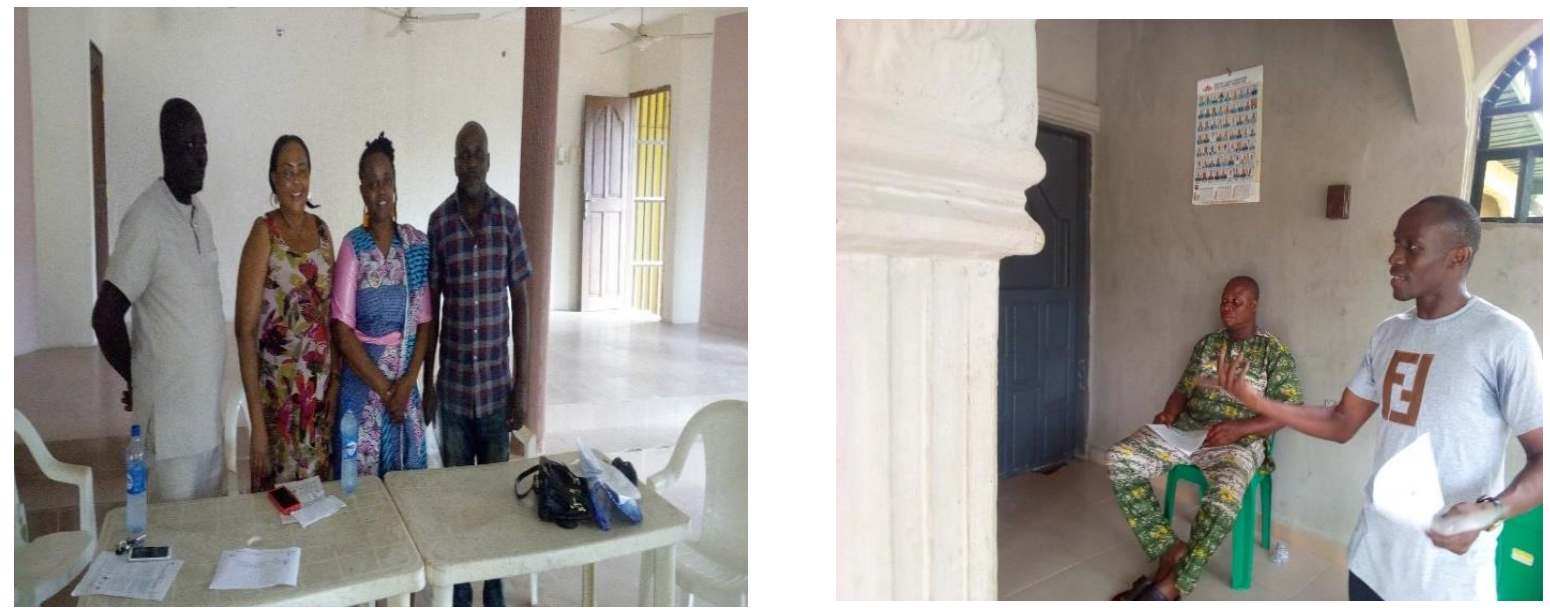

DreamBoat Executive director $\left(2^{\text {nd }}\right.$ right) pose for a photograph with Akai Effa Community ( $3^{\text {rd }}$ Left) and other senior Cabinet members during an advocacy visit
DreamBoat TDF Senior Programs Officer making a presentation during advocacy visit in Idundu Community, Akpabuyo LGA 

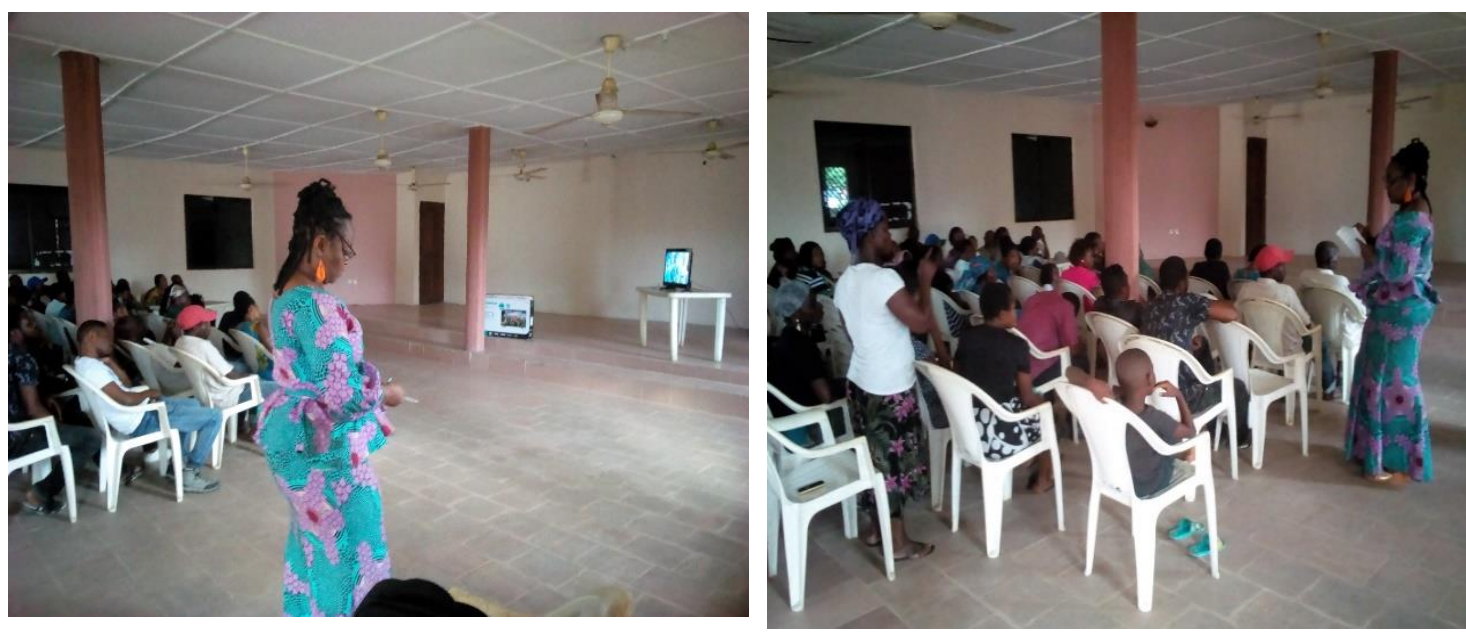

Cross Section of Akai Effa Community Members watching the Film "Women of our Land" during DreamBoat/Goethe Film Tour

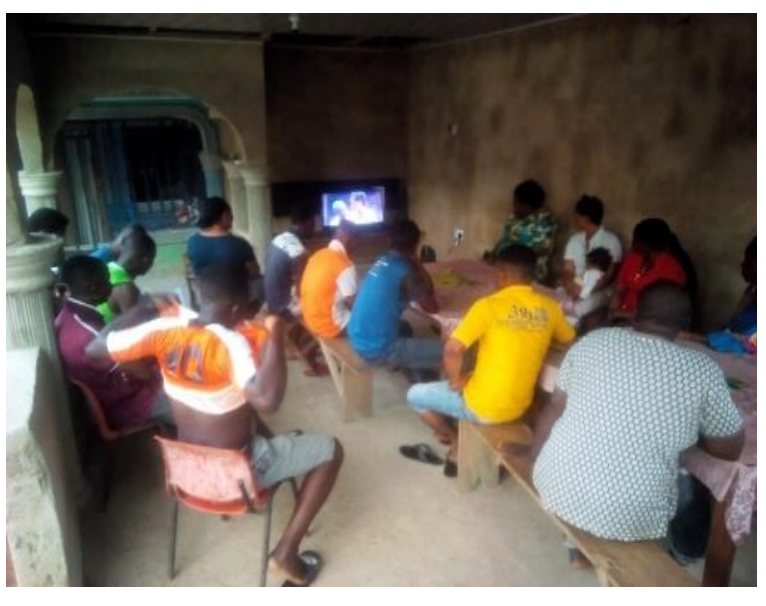

Community Members in Idundu, Akpabuyo LGA watching the Film "Women of our Land" during film tour in their area

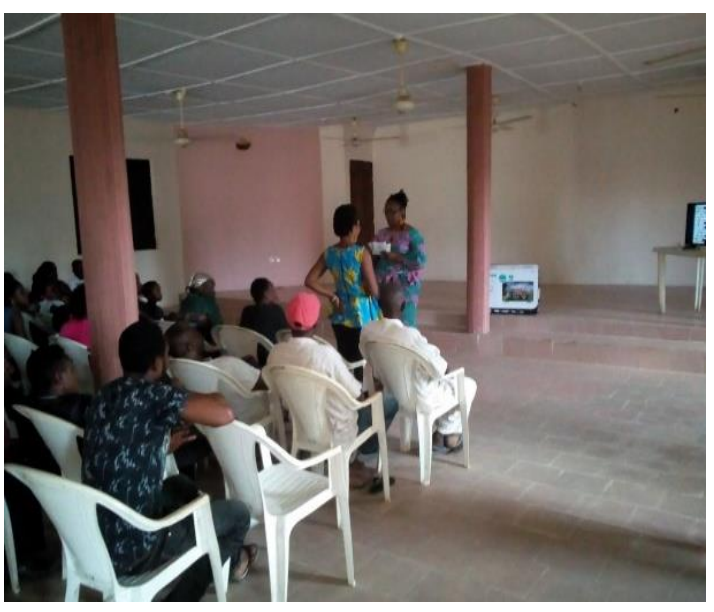

Interactive session with Akai Effa Community Members after watching the film "Women of our Land"

\section{RESULTS AND DISCUSSION}

\section{Film Tour And Community Engagement}

\section{Aka Effa}

The first community visited was Akai Effa in Calabar Municipality, Cross River State. On the appointed day, the community gathered about an hour before time. They rolled out their drums and began to sing folk songs. 
When DreamBoat team arrived in the town hall, they were excited. After pleasantries, The film 'Women of our Land' was shown, after which the facilitator, began an interactive question and answer session with community members. In response to which of the stories touched them most they pointed out the following;

1. The story of the man that threatened to stop his wife, Lydia operating her restaurant business because she was returning late

2. The story of Asandia's husband, Odusu not allowing his daughters to go to school, insisting Esine the first daughter be married early and the wife should produce more male children

3. The story of Madam Ayi's land taken from her by her husband's relatives

4. The story of Odusu pursuing the wife with a matchet

5. The rape of Esaime

6. When probed to find out why these stories touched them, some said

i. They happen in Akai Effa

ii. They remind us of what we face

iii. This is the reality of our lives

Two issues generated a lot of heat, i.e. were burning

i. Wife battery and domestic violence

ii. The issue of not allowing women to work

Many women spoke out against these and men tried to counter them

\section{According to some men;}

'Women are traditionally meant to be at home and cater to their spouses and children'

'women who work are unfaithful to their husbands'

'women suppress their husbands when they have money'

'when women work they become proud, arrogant and insubordinate'

'if my wife works let her go...period!'

Many women believe that women not working is a major cause of much gender-based violence in the community. Women also say they need to work to help themselves and their children as men are selfish and never give enough.

The other issue that is burning is domestic violence.

The chief reported that" many times I have been called to settle cases of men who beat their wives with a matchet. This has to stop". Some men opposed this stance.

Many of the men felt that 'the women are our properties we can do what we like... I will not stop beating my wife. Such comments brought a lot of acrimony during the sessions. There were a few men that felt different but they are a minority. The facilitators briefly talked about the concept of gender and asked them the way forward.

\section{Idundu Community}

The second community visited was Idundu community situated in Akpabuyo Local Government Area of Cross River State.

The Youth leader who was assigned the responsibility to work with the organization in making the project a success in the community was contacted, he repeatedly shifted the data many times. He finally set a date for the community film tour. On the date scheduled for the event, the DreamBoat team arrived the community at $3 \mathrm{pm}$, which was the time scheduled for the activity to take place, on arrival, it took another one hour thirty minute before the event finally commenced which was the reason the event was concluded in the night. 
When the DreamBoat team arrived the venue the chief initially communicated to the team that the event will take place, was no longer available; the Youth leader had to make fresh arrangements in another community members' compound and then gathered community members who watched the GBV film. The event started slowly with few persons but before long community members started trouping in. After pleasantries, the 60 minutes GBV film, "Women of our Land" was played. At the end of the film shows one of the lead facilitators, engaged the community members in an interactive session where questions were asked and answers provided. In regards to what the story is all about, almost every community member could mention that it was about different problems happening in families and communities. This was about which part of the story captivated them most. They pointed out the following;

1. Most of the community members said it was the rape scene (their reaction shows it is serious in the community contrary to what the Community Chief said during the advocacy visit).

2. Few community members said the story of the father asking the daughter not to marry but to bear a child for the family was what tickled the fantasy.

3. The story of Madam Ayi's land taken from her by her husband's relatives

4. The scene that women were given their right at the end of the film and they were to be empowered

Further probing to elucidate why they were touched by the storyline they mentioned, some three key incidents of rape that had happed in the community. The incidents are as follows:

1. One of the participants narrated a story of how an elderly man in the community raped a baby and destroyed her body parts. The man was disgraced

2. Another scenario is the case were two young men raped a young girl in her early teenage age repeatedly for a long while before they were caught and handed over to the police, they have run away from the community permanently

3. The third story is that of a step-father that impregnated the daughter-in-law and the mother at the same time

The key issues that generated a lot of heated arguments and reactions were centred around rape in the community. Also, like in Akai Effa community;

1. Partners' violence

2. Girl child abuse by older men especially those who hawk for the parents or guardians

3. Wife battery and domestic violence

This activity provided a platform for most women to air out their feelings about genderbased violence. Some of them accused the men of not doing enough to deal with offenders when women and girls are being abused, adding that most times the culprits go away not dealt with. The men on the other hand disagreed and pointed out instances when they apprehended the culprits and handed them over to the police, some have left the community never to return and so many other instances. On the part of the men, they also agreed that almost all the issues shown on "Women of Our Land" are what has happened in their community and they have done their best to combat the ones they are aware of.

\section{Some Men Made The Following Statements}

i. 'I am the secretary of the Ward Development Committee; I have been part of those that stand my ground when issues of rape are reported. Sometimes we track the offender and take them to police"

ii. Any man that says a woman should not work does not know what she/he is doing. In this generation, you cannot tell what will happen in the future and your wife or partner may be your supporter' 
iii. 'If it is education, I do not have any preference, I cannot say I will not train my daughter because of my son, others can do it but for me, I won't because you cannot tell which of your children will take care of you tomorrow; so to me it is foolishness not to train a girl child'

iv. 'Please, I want to ask, is it right for these big men to be molesting these young girls when they go to sell for them because that is what is happening here. These old men want to finish our girls for us...o'

A particular woman was so bitter with what men were doing with girls young enough to be their daughters. However, some of the men blamed some of the young girls of running after men bigger than them. One of the men reported a young girl in the community who is still in primary six but will leave home to sleep with men and that one of the guys even organized a birthday party for her recently and at this point asked, "is it the fault of the men sleeping with her to give her money at that age".

It is worthy to note that reactions and responses of the two communities, while the Akai Effa Chief and people readily opened up, Idundu community members tried to cover and tried to stall the project. Historically there still exist unequal power relations between men and women. Women are often not given equal opportunities as men in their families, in the communities, and by state.

Deprivations and discriminatory cultural norms have forced many girls to marry at a young age and have made them vulnerable to HIV, sexual violence, and physical exploitation. Women and girls lack a full range of economic opportunities and are devalued because of gender bias, many girls are seen as unworthy of investment or protection by their families, isolated and unsupported. These women and girls have little voice to demand their rights (UNDP 2018, pp. 88). Gender-based violence, which stems from the perceived social inferiority of women, makes it impossible for women to build their capacities and exercise their rights. Women who suffer such violence cannot escape from poverty, as they are subjected to degrading relationships that undermine their standing in both the private and the public spheres, thereby making them vehicles for the intergenerational transmission of poverty (UNFPA 2016, pp. 228).

The communities made the following suggestions as a way forward.

Akai Effa community

More training on gender for men and women

Involvement of faith-based groups and other cultural groups

Empowerment for women

Loans for women to do business

Linking victims and culprits to women protection Agency and customary courts as well as primary health facilities.

\section{Idundu community}

1. Community leaders should do more to ensure the culprit of rape and other related violence against women and girls are brought to book

2. Families should be empowered adequately to prevent them from sending their girls to go and hawk as this exposes them as prey to the rare men and boys

3. Parents should be proactive in monitoring and disciplining their children to protect them from unnecessary molestation.

These suggestions led to the formation of Neighborhood Human Rights Committee 


\section{Formation Of Neigbourhood Human Rights And Health Committees}

To reduce Gender-Based Violence in the communities, two neighborhood communities, human rights were formed in Akai Effa and one in Idundu community. The activities took place on two different days in the two communities. Before the meeting, the community leaders were asked to send names of active persons in their communities including those already in the Ward Development Committee to be part of the committee. This was done and they were inaugurated accordingly. Their mandate is to look out for any Gender-Based Violence in the communities, help victims access justice, and assist in integrating survivors back to the communities (Godwin et al., 2015). They are to work with the security, health facilities, and Courts located in their community in collaboration with their community leaders to achieve this task. They promise to do their best to ensure the aim is achieved because it is for the good of the community. The two health committees are to work with the organization to achieve the task of addressing the issues of gender-based violence in their communities.

\section{Findings}

Gender-based violence in the two communities manifest in several ways; that can be summarized as such

1. Domestic violence, especially wife battery

2. Restrictions placed on women's economic activities

3. Sexual harassment and rape of many young girls

4. Loss of land, assets, properties

5. Young girls denied the opportunity to go to school

The findings of this study correlate with several studies on gender in different communities in Nigeria and across the world (Herbert et al., 2020, pp. 19). Gender norms affect women more than men. It influences their whole lives, it determines

i. Whether they will work or even the type of work they are allowed to do

ii. Whether they go to school or type of school they will go

iii. The value attached to women are they seen as 'toys' sexual objects, properties.

iv. Their relationship and marriage in these turn affects the way they are treated; are they treated with respect or used as punching bags, sexually harassed, abused psychologically, verbally, and emotionally.

Understanding the contexts in which gender-based violence occurs is a critical part of designing programmes for men and women to support a community's overall welfare scheme.

following:

The work in these communities brought out several lessons which include the

1. The need to work with key champions to change social norms, changing the community's notion of their beliefs about women and girls that contribute to gender inequality can only be done gradually. It is important to adopt a measured approach and work with a small number (as champions) who will in turn influence their families, friends, and communities.

2. The need to offer opportunities to marginalised women to boost their self-esteem; Involving women from rural communities in training, dialogues and discussions on gender help boost their and their network's confidence and self-esteem. They come out of their shell and exhibit their latent talent

3. Incorporating a range of vocational and life skills in awareness creation programmes deepens participation and involvement of women

4. Community members put a lot of trust in Civil Society Organisations (CSOs) as well as expectations. CSOs have a positive impact on the lives of community members. 
5. Poverty is so much in the communities especially among women and any project brought to the community even when it will provide benefits for them is seen as an avenue that to make money or get an allowance to support the participants and their families.

6. Adhering to traditional roles of masculinity and Feminism is an important driver in the perpetuation of gender inequalities and violence in our communities.

\section{CONCLUSION}

In conclusion, the study was innovative, exciting, and engaging. The narrative-based research methods provided an opportunity for community members to speak freely even touching on taboo topics! It allowed the community to reflect on their practices and attitudes. Findings from this study can best be summarized by the words of Luciana Herbert et al (2020, pp. 16) Cross River's persistent gender inequality and violence will require a multi-pronged approach solution and interventions addressing socio-cultural norms, structures, education, and economic factors.

\section{REFERENCES}

Bandura, A., \& Walters, R.H. (1963). Social learning and personality development. Holt Rinehart and Winston: New York.

Bassey, S. A., \& Bubu, N. G. (2019). Gender inequality in Africa: a re-examination of cultural values. Cogito: Multidisciplinary Res. J., 11, 21.

Chika, I. S., (2012). "Gender-Based Domestic Violence in Nigeria." Indian Journal of Gender Studies 19(1):137-48.

Edor, J. E. (2016). Capital punishment: focus on the sanctity of human life in (Boki). Sapientia: Journal of Philosophy 6 (April), 86-102

Edor, J. E., \& Ayuk, T. O. (2020). Religious Extremism: A threat to Nigerian Corporate Existence. Journal of the Social Sciences. 48(2).

Endong, F. P. C. (2017). The Female Media Producer as an Advocate of Women's Empowerment in Nigeria: The Cross River State Experience. Gender Studies, 15(1), 167182. https://doi.org/10.1515/genst-2017-0011

Godwin, M. U., Iwuchukwu, C. S., \& Atsu, E. M. (2015). Human rights, language use and societal abuse in cross river state, Nigeria. Mediterranean Journal of Social Sciences, 6(1S1), 210-217. https://doi.org/10.5901/mjss.2015.v6n1s1p210

Hebert, L. E., Bansal, S., Lee, S. Y., Yan, S., Akinola, M., Rhyne, M., Menendez, A., \& Gilliam, M. (2020). Understanding young women's experiences of gender inequality in Lucknow, Uttar Pradesh through story circles. International Journal of Adolescence and Youth, 25(1), 1-11.

Ibok, A. K., \& Ogar, O. T. (2018). Traditional Roles of African Women in Peace Making and Peace Building: An Evaluation. GNOSI: An Interdisciplinary Journal of Human Theory and Praxis, 1(1), 41-58.

Mayen, U. G. (2018). Diasporic culture, Cultural transformation and grass root development in Francophone Africa. Lwati: A Journal of Contemporary Research, 15(2), 134-153.

Njoku, F. O. C (2002). Essays in African Philosophy, Thought and Theology. Enugu: Snaap Press LTD, 31.

Njoku, J. N., Osang, E. A., \& Ntamu, B. A. (2020). Social Variables and Dropout Tendencies among Secondary School Students in Ikom Education Zone, Cross River State, Nigeria. International Education Studies, 13(8), 88. https://doi.org/10.5539/ies.v13n8p88

Peate, I. (2019). "Gender-Based Violence." British Journal of Nursing 28(10):607. 
Renzetti, C. M., (2005). “Gender-Based Violence.” Lancet 365(9464):1009-10.

Uko, S. (2004). Gender, leadership styles and administative effectiveness of principals in Cross River State. Global Journal of Educational Research, 1(1). https://doi.org/10.4314/gjedr.v1i1.29383

Umukoro, G. M. (2015). La Sexualite Dans La Societe Aujourd'hui; Reflexion Sur Les Activites De La Fete De Noël De Calabar. Journal of Modern European Languages And Literatures, 4, 32-40.

Umukoro, G. M., \& Egbai, M. J. (2016). Gender Mainstreaming, A Panacea For Quality Service And Good Governance: An Insight Into The Political Systems In Francophone Africa. Global Journal of Applied, Management and Social Sciences, 11.

UNDP. (2018). Human Development Indices and Indicators. 2018 Statistical Update. United Nations Development Programme, 27(4), 123.

UNFPA. (2016). Universal Access to Reproductive Health: Progress and challenges. UNFPA, January, 1-21.

Ventevogel, P. (1996). Whiteman's things: training and detraining healers in Ghana. In Health, culture and society.

Webster, J. (2019). A literature review of the views and experiences of midwives who screen for domestic violence. MIDIRS Midwifery Digest, 29(2), 183-188.

Yta, E. M., \& Umukoro, G. M. (2018). Adjudication and" Band of the Year Award": A Case Study of the Masta Blasta Carnival Calabar Band. Journal of Theatre \& Media Studies, 3(1). 